\title{
On the best locations for ground-based polar stratospheric cloud (PSC) observations
}

\author{
Matthias Tesche ${ }^{1}$, Peggy Achtert ${ }^{2}$, and Michael C. Pitts ${ }^{3}$ \\ ${ }^{1}$ Leipzig Institute for Meteorology (LIM), Leipzig University, Stephanstrasse 3, 04103 Leipzig, Germany \\ ${ }^{2}$ Meteorological Observatory Hohenpeißenberg, German Weather Service (DWD), Germany \\ ${ }^{3}$ NASA Langley Research Center, Hampton, Virginia 23681, USA
}

Correspondence: Matthias Tesche (matthias.tesche@uni-leipzig.de)

Received: 3 September 2020 - Discussion started: 29 September 2020

Revised: 26 November 2020 - Accepted: 27 November 2020 - Published: 15 January 2021

\begin{abstract}
Spaceborne observations of polar stratospheric clouds (PSCs) with the Cloud-Aerosol LIdar with Orthogonal Polarization (CALIOP) aboard the Cloud-Aerosol Lidar and Infrared Pathfinder Satellite Observations (CALIPSO) satellite provide a comprehensive picture of the occurrence of Arctic and Antarctic PSCs as well as their microphysical properties. However, advances in understanding PSC microphysics also require measurements with ground-based instruments, which are often superior to CALIOP in terms of, for example, time resolution, measured parameters, and signalto-noise ratio. This advantage is balanced by the location of ground-based PSC observations and their dependence on tropospheric cloudiness. CALIPSO observations during the boreal winters from December 2006 to February 2018 and the austral winters 2012 and 2015 are used to assess the effect of tropospheric cloudiness and other measurement-inhibiting factors on the representativeness of ground-based PSC observations with lidar in the Arctic and Antarctic, respectively. Information on tropospheric and stratospheric clouds from the CALIPSO Cloud Profile product (05kmCPro version 4.10) and the CALIPSO polar stratospheric cloud mask version 2 , respectively, is combined on a profile-by-profile basis to identify conditions under which a ground-based lidar is likely to perform useful measurements for the analysis of PSC occurrence. It is found that the location of a ground-based measurement together with the related tropospheric cloudiness can have a profound impact on the derived PSC statistics and that these findings are rarely in agreement with polewide results from CALIOP observations. Considering the current polar research infrastructure, it is concluded that the most suitable sites for the expansion of capabilities
\end{abstract}

for ground-based lidar observations of PSCs are Summit and Villum in the Arctic and Mawson, Troll, and Vostok in the Antarctic.

\section{Introduction}

The existence of polar stratospheric clouds (PSCs) is of critical importance for stratospheric ozone depletion during polar winter. They provide the surface for heterogeneous reactions which transform stable chlorine and bromine species into their highly reactive ozone-destroying states (Lowe and MacKenzie, 2008; Solomon, 1999). PSC formation requires low temperatures that support the condensation of stratospheric water vapour and nitric acid vapour onto the available stratospheric aerosol particles. These conditions are generally found from December to February in the Arctic and between late May and early October in the Antarctic (Pitts et al., 2018).

Since the early 1990s, airborne and ground-based lidar remote-sensing observations of PSC optical properties have been used to classify PSCs into different types according to their size, shape, and chemical composition (Achtert and Tesche, 2014). Detailed observations of PSC occurrence and composition are also available from passive remote-sensing observations with the Michelson Interferometer for Passive Atmospheric Sounding (MIPAS) instrument (Spang et al., 2018). Today, there is consensus that PSC particles consist of supercooled liquid ternary solution (STS), nitric acid trihydrate (NAT) crystals, or water ice (ice) and that PSCs are made up of different mixtures of those three components. 
Ground-based lidar observations of PSCs are generally performed at the mercy of tropospheric clouds. Since its launch in June 2006, the Cloud-Aerosol LIdar with Orthogonal Polarization (CALIOP) aboard the Cloud-Aerosol Lidar and Infrared Pathfinder Satellite Observations (CALIPSO) satellite (Winker et al., 2009) has been providing a polewide view of Arctic and Antarctic PSCs that is unaffected by tropospheric cloudiness. The initial CALIPSO PSC classification scheme employs light-scattering calculations that consider spherical and non-spherical particle shapes to relate sets of optical parameters to microphysical properties (Pitts et al., 2009, 2013). Recently, the CALIPSO polar stratospheric cloud mask version 2 was introduced to correct deficiencies of the initial CALIPSO PSC classification and to improve composition discrimination (Pitts et al., 2018).

Traditionally, two approaches are used to match groundbased lidar measurements to spaceborne observations. Either statistics from a time series of ground-based measurements are compared to those obtained from averaging spaceborne observations for a specific grid box around the ground station or individual ground-based observations are matched to the data of the closest CALIPSO approach (Snels et al., 2019). Both methods can introduce biases as a result of imperfect temporal or spatial collocation. In addition, ground-based and spaceborne lidar observations of PSCs are often analysed with customised retrieval algorithms that can vary in their definition of different PSC types (Achtert and Tesche, 2014). The combined data set of CALIPSO cloud observations in the troposphere and stratosphere during the Arctic winters from December 2006 to February 2018 and the Antarctic winters 2012 and 2015 presented here allows for an assessment of the effect of tropospheric cloudiness and other measurement-inhibiting factors on the representativeness of ground-based lidar measurements of PSCs in a novel way. This paper starts with a description of the data and methods in Sect. 2. Results are presented and discussed in Sect. 3, and conclusions are drawn in Sect. 4.

\section{Data and methods}

\subsection{Ground stations}

Figure 1 and Table 1 provide an overview of the Arctic and Antarctic research stations considered here. The sites were selected because they are accessible, manned year-round, and assumed to provide the necessary infrastructure for groundbased lidar measurements. Sites are also selected to minimise overlap with other research stations. Emphasised are the established PSC observatories Esrange, Sweden (Blum et al., 2005); Eureka, Canada (Donovan et al., 1997); Ny Ålesund, Svalbard (Massoli et al., 2006); and Sodankylä, Finland (Müller et al., 2001) in the Arctic and Belgrano II (Córdoba-Jabonero et al., 2013); Concordia (Snels et al., 2020); Dumont d'Urville (David et al., 1998; Santecesaria et
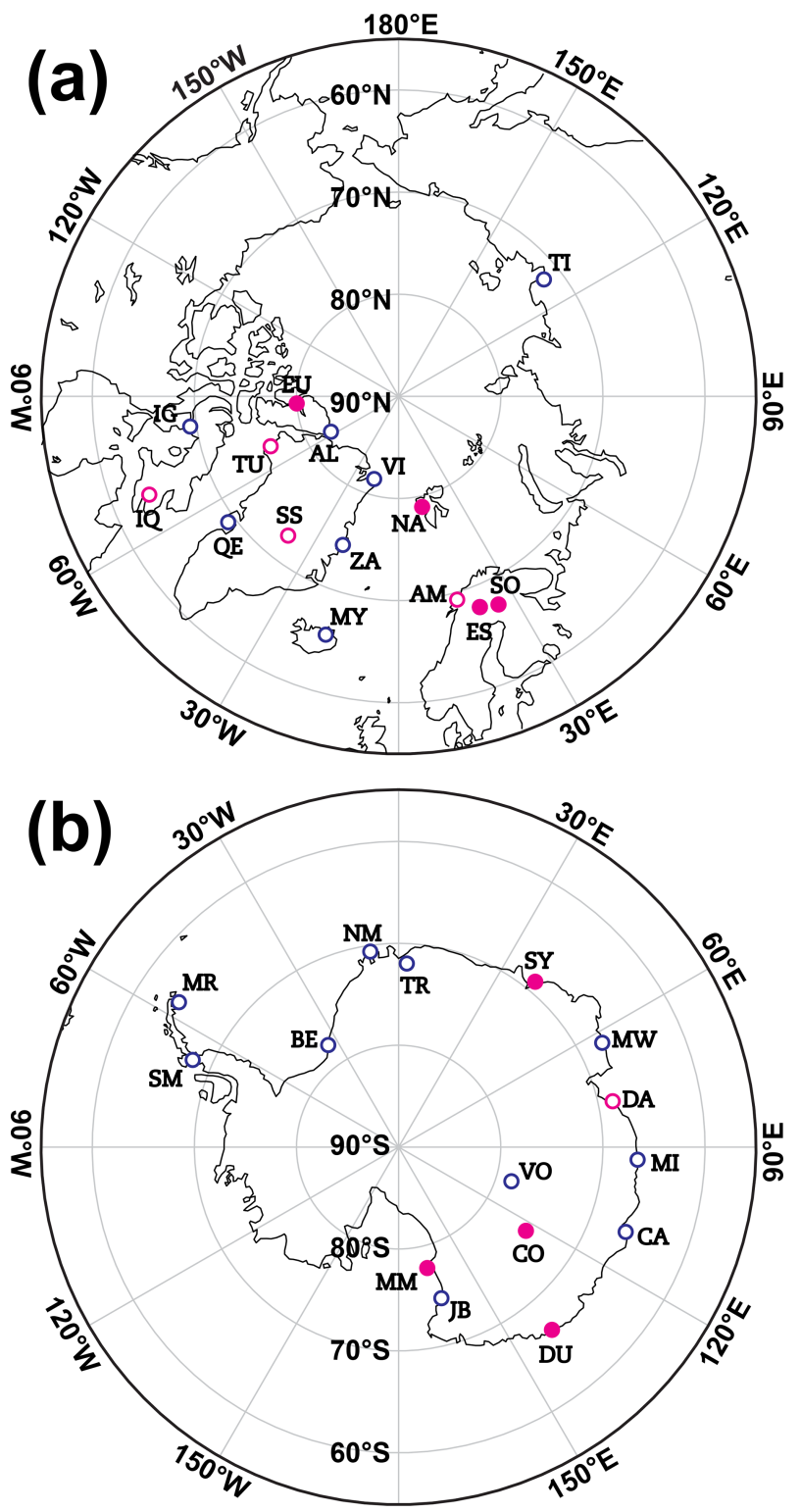

Figure 1. Locations of research stations in (a) the Arctic and (b) the Antarctic and their respective abbreviations as listed in Table 1. Red open circles mark stations with atmospheric lidar measurements, while red filled circles refer to stations with published PSC measurements. Other stations of potential interest for ground-based PSC observations are marked by blue open circles.

al., 2001); McMurdo (Adriani et al., 2004; Snels et al., 2019); and Syowa (Shibata et al., 2003) in the Antarctic. Also highlighted are stations with a record of lidar measurements that are not specifically dedicated to PSC observations: Alomar (Langenbach et al., 2019), Iqualuit, and Summit (Neely et al., 2013) in the Arctic and Davis in the Antarctic. 
Table 1. Overview of the location of Arctic and Antarctic research stations. Station abbreviations in the first and fifth columns are used to mark the corresponding sites in Figs. 1 and $8 . R$ gives the ratio of PSC height bins for tropospheric cloudiness that relates to the data coverage of a ground-based (cloud-free and transparent clouds) and a spaceborne lidar (all sky).

\begin{tabular}{|c|c|c|c|c|c|c|c|}
\hline \multicolumn{2}{|c|}{ Arctic station } & \multirow{2}{*}{$\begin{array}{l}\text { Location } \\
82^{\circ} \mathrm{N}, 62^{\circ} \mathrm{W}\end{array}$} & \multirow{2}{*}{$\begin{array}{l}R \\
0.59\end{array}$} & \multicolumn{2}{|c|}{ Antarctic station } & \multirow{2}{*}{$\begin{array}{l}\text { Location } \\
78^{\circ} \mathrm{S}, 35^{\circ} \mathrm{W}\end{array}$} & \multirow{2}{*}{$\begin{array}{l}R \\
0.57\end{array}$} \\
\hline AL & Alert, Canada & & & $\mathrm{BE}$ & Belgrano II, Coats Land ${ }^{\mathrm{b}}$ & & \\
\hline $\mathrm{AM}$ & Alomar, Norway & $69^{\circ} \mathrm{N}, 16^{\circ} \mathrm{E}$ & 0.42 & $\mathrm{CA}$ & Casey, Vincennes Bay & $66^{\circ} \mathrm{S}, 111^{\circ} \mathrm{E}$ & 0.60 \\
\hline ES & Esrange, Sweden ${ }^{b}$ & $68^{\circ} \mathrm{N}, 21^{\circ} \mathrm{E}$ & 0.51 & $\mathrm{CO}$ & Concordia, Antarctic Plateau ${ }^{\mathrm{b}}$ & $75^{\circ} \mathrm{S}, 123^{\circ} \mathrm{E}$ & 0.99 \\
\hline EU & Eureka, Canada ${ }^{b}$ & $80^{\circ} \mathrm{N}, 86^{\circ} \mathrm{W}$ & 0.74 & DA & Davis, Princess Elizabeth Land ${ }^{\mathrm{a}}$ & $69^{\circ} \mathrm{S}, 78^{\circ} \mathrm{E}$ & 0.71 \\
\hline IG & Igloolik, Canada & $69^{\circ} \mathrm{N}, 82^{\circ} \mathrm{W}$ & 0.71 & DU & Dumont d'Urville, Aélie Land ${ }^{b}$ & $66^{\circ} \mathrm{S}, 140^{\circ} \mathrm{E}$ & 0.70 \\
\hline IQ & Iqaluit, Canada ${ }^{\mathrm{a}}$ & $64^{\circ} \mathrm{N}, 69^{\circ} \mathrm{W}$ & 0.92 & $\mathrm{JB}$ & Jang Bogo, Terra Nova Bay & $75^{\circ} \mathrm{S}, 164^{\circ} \mathrm{E}$ & 0.74 \\
\hline MY & Myvatn, Iceland & $66^{\circ} \mathrm{N}, 17^{\circ} \mathrm{W}$ & 0.46 & MR & Marambio, Marambio Island & $64^{\circ} \mathrm{S}, 57^{\circ} \mathrm{W}$ & 0.43 \\
\hline NA & Ny Ålesund, Svalbard ${ }^{b}$ & $79^{\circ} \mathrm{N}, 12^{\circ} \mathrm{E}$ & 0.29 & MW & Mawson, Mac Robertson Land & $68^{\circ} \mathrm{S}, 63^{\circ} \mathrm{E}$ & 0.83 \\
\hline QE & Qeqertarsuaq, Greenland & $69^{\circ} \mathrm{N}, 54^{\circ} \mathrm{W}$ & 0.51 & MM & McMurdo, Ross Island ${ }^{\mathrm{b}}$ & $78^{\circ} \mathrm{S}, 167^{\circ} \mathrm{E}$ & 0.71 \\
\hline SO & Sodankylä, Finland ${ }^{\mathrm{b}}$ & $67^{\circ} \mathrm{N}, 27^{\circ} \mathrm{E}$ & 0.42 & MI & Mirny, Davis Sea & $67^{\circ} \mathrm{S}, 93^{\circ} \mathrm{E}$ & 0.85 \\
\hline SS & Summit Station, Greenland ${ }^{\mathrm{a}}$ & $73^{\circ} \mathrm{N}, 39^{\circ} \mathrm{W}$ & 0.99 & NM & Neumayer III, Atka Bay & $71^{\circ} \mathrm{S}, 8^{\circ} \mathrm{W}$ & 0.60 \\
\hline TU & Thule, Greenland ${ }^{\mathrm{a}}$ & $77^{\circ} \mathrm{N}, 69^{\circ} \mathrm{W}$ & 0.73 & SM & San Martín, Barry Island & $68^{\circ} \mathrm{S}, 67^{\circ} \mathrm{W}$ & 0.45 \\
\hline TI & Tiksi, Russia & $72^{\circ} \mathrm{N}, 129^{\circ} \mathrm{E}$ & 0.52 & SY & Syowa, Queen Maud Land ${ }^{\mathrm{b}}$ & $69^{\circ} \mathrm{S}, 40^{\circ} \mathrm{E}$ & 0.58 \\
\hline VI & Villum, Greenland & $82^{\circ} \mathrm{N}, 17^{\circ} \mathrm{W}$ & 0.54 & TR & Troll, Queen Maud Land & $72^{\circ} \mathrm{S}, 3^{\circ} \mathrm{E}$ & 0.85 \\
\hline $\mathrm{ZA}$ & Zackenberg, Greenland & $75^{\circ} \mathrm{N}, 21^{\circ} \mathrm{W}$ & 0.73 & $\mathrm{VO}$ & Vostok, Antarctic Ice Sheet & $78^{\circ} \mathrm{S}, 106^{\circ} \mathrm{E}$ & 1.00 \\
\hline
\end{tabular}

${ }^{a}$ Stations with a deployment of atmospheric lidar instruments. ${ }^{b}$ Stations with existing PSC data sets.

\subsection{Cloud Profile data}

Information on tropospheric clouds is taken from the CALIPSO level 2 version 4.10 Cloud Profile product $(05 \mathrm{~km}-$ CPro.v4.10), which provides information on the vertical extent of different cloud types as well as profiles of the optical properties of clouds with a resolution of $5 \mathrm{~km}$ along the CALIPSO ground track and $30 \mathrm{~m}$ height bins below $8.2 \mathrm{~km}$ height ( $60 \mathrm{~m}$ height bins between 8.2 and $20.2 \mathrm{~km}$ height). The extracted parameters are time, latitude, longitude, and the cloud type as provided in the Vertical Feature Mask product.

Features that are identified as clouds in the CALIPSO retrieval are further classified into eight cloud types (Liu et al., 2009): (i) low overcast, transparent; (ii) low overcast, opaque; (iii) transition stratocumulus; (iv) low, broken cumulus; (v) altocumulus (transparent); (vi) altostratus (opaque); (vii) cirrus (transparent); and (viii) deep convective (opaque). Ground-based equivalent CALIPSO observations are those that show an absence of tropospheric clouds or only transparent clouds for which a human operator would likely consider performing a ground-based measurement, i.e. transparent altocumulus, cirrus, or a combination of the two. An overview of the number of considered CALIPSO profiles with PSC observations for different tropospheric cloudiness is presented in Table 2.

\subsection{Polar stratospheric cloud mask version 2}

The CALIOP version 2 PSC detection and composition classification algorithm (CALIPSO polar stratospheric cloud mask v2) separates stratospheric cloud features into STS,
Table 2. Number of considered CALIPSO profiles with PSC observations for different tropospheric cloudiness in the Arctic (December 2006 to February 2018) and the Antarctic (winters of 2012 and 2015). The sum of cloud-free conditions and profiles with transparent clouds makes up the view of a ground-based lidar.

\begin{tabular}{lrr}
\hline Tropospheric cloudiness & Arctic & Antarctic \\
\hline All sky & 1000572 & 1676986 \\
Cloud free & 218553 & 402630 \\
Transparent & 225600 & 740952 \\
Ground based & 444153 & 1143582 \\
\hline
\end{tabular}

NAT mixture, ice, NAT enhanced, and wave ice. The polar stratospheric cloud mask product has an along-track resolution of $5 \mathrm{~km}$, identical to the tropospheric CALIPSO products, and a vertical resolution of $180 \mathrm{~m}$. The new CALIPSO polar stratospheric cloud mask corrects known deficiencies in previous versions (Pitts et al., 2009, 2013) and is described in detail in Pitts et al. (2018). A first evaluation with groundbased measurements at Antarctica is presented in Snels et al. (2019).

While all boreal winters from December 2006 to February 2018 are considered in the analysis of Arctic PSCs, only the austral winters of 2012 and 2015 are included in the analysis of Antarctic PSCs. However, the generally higher occurrence rate of Antarctic PSCs means that a larger number of individual PSC profiles was observed during the 2 Antarctic winters compared to the 12 considered Arctic winters (see Table 2).

Because of CALIPSO's top-down viewing geometry, profiles start with the uppermost height bin (bin 1) down to the 
lowermost height bin (bin 583). Profiles in the CALIPSO polar stratospheric cloud mask v2 product extend down to $8.2 \mathrm{~km}$. They can therefore contain contributions of uppertropospheric cirrus, as visualised in Figs. 13 and 20 of Pitts et al. (2018). To exclude the contribution of such cirrus clouds from our analysis, only height bins above $14.9 \mathrm{~km}$ (smaller than bin 85) and $13.1 \mathrm{~km}$ (smaller than bin 96) are considered to represent Arctic and Antarctic PSC, respectively.

\subsection{Data analysis}

Information on cloud type from the Vertical Feature Mask in the 05kmCPro.v4.10 Cloud Profile product is used to sum up the number of height bins with different tropospheric cloudiness for each CALIPSO profile. This information is used to identify cloud-free conditions (a total of zero counts for each of the eight cloud types) and situations with only transparent tropospheric clouds that would still enable meaningful PSC observations with a ground-based lidar, i.e. altocumulus (transparent), cirrus (transparent), or a combination of the two. In addition, all sky refers to the use of all profiles independent of tropospheric cloudiness.

The CALIPSO polar stratospheric cloud mask v2 is processed analogous to the Vertical Feature Mask for tropospheric clouds by accumulating the number of height bins with different PSC composition for each CALIPSO profile. PSCs that extend over just one height bin are excluded from the analysis. A CALIPSO profile is referred to as containing a certain PSC composition (e.g. STS-containing or icecontaining profiles) if the respective component is identified in at least one of the PSC height bins.

To enable a combined analysis of cloudiness in the polar troposphere and stratosphere, the data extracted from the $05 \mathrm{kmCPro.v4} .10$ and polar stratospheric cloud mask v2 products are temporally matched and reduced to only those profiles with detected PSCs. The data set is then filtered according to the occurrence of (i) tropospheric clouds and (ii) PSCs with different composition. The filtered data are gridded into cells of $1.25^{\circ}$ latitude by $2.50^{\circ}$ longitude for visualisation of PSC occurrence. Maps of the occurrence of the accumulated number of height bins related to different PSC compositions are normalised by the total number of PSC height bins per considered grid box (see Figs. 2, 3, 5, and 6).

The matched observations of tropospheric and stratospheric clouds allow for a direct comparison of individual PSC profiles as well as long-term PSC statistics as seen from ground and space independent of the considered instruments. Specifically, the same profile can be evaluated from two perspectives, i.e. from space as well as from the point of view of a ground-based instrument. In that context, the latter perspective translates to a CALIPSO-synchronous measurement protocol at a ground station. True PSC statistics unaffected by tropospheric cloudiness, i.e. during all-sky conditions, at a certain location can only be obtained with a spaceborne lidar. In contrast, filtering with respect to tropospheric cloudiness is applied to emulate the likely conditions for meaningful ground-based PSC measurements in the CALIPSO data set. Specifically, we assume that a ground-based lidar would only provide meaningful results during conditions with no clouds or only transparent clouds that would not already attenuate the laser beam before it can reach PSC altitudes. This is referred to as the ground-based view of the CALIPSO data set. It provides sampling that is dependent on the CALIPSO return rate and must not be confused with actual ground-based measurements that can provide localised PSC observations in the time range from hours to weeks.

We subsequently separate the ground-based view of the CALIPSO data set into two scenarios for which (i) all cases of the ground-based view are considered and (ii) one-third of the profiles of the ground-based view was randomly selected. The first scenario corresponds either to a continuously operating lidar or a manually operated system that is active during every single CALIPSO overpass with possible downtime in between without any interference by tropospheric clouds or measurement-inhibiting factors. The second scenario also refers to CALIPSO-synchronous measurements with the caveat that interfering factors reduce the number of measured lidar profiles to one-third of what would ideally be possible. This latter scenario is much more realistic as (i) most ground-based lidar instruments are operated manually and on campaign basis; (ii) the decision to start a measurement, i.e. the assessment of tropospheric cloudiness, is made subjectively by the operator; and (iii) infrastructural challenges (e.g. system downtime, logistical problems, and lack of personnel) affect the operation of a ground-based lidar at a remote location and under harsh conditions.

To assess the representativeness of ground-based PSC measurements, PSC statistics are obtained for boxes of $2^{\circ}$ latitude by $2^{\circ}$ longitude around the sites in Fig. 1 and Table 1 .

\section{Results and discussion}

\subsection{Arctic observations}

The absolute number of observed PSC profiles (normalised to a maximum count of 2478) and the PSC occurrence rate (the ratio of observed CALIPSO PSC profiles versus all CALIPSO profiles) are shown in Fig. 2a and b, respectively. The absolute number of PSC observations is largest at highest latitudes due to the high CALIPSO return rate at those locations. The effect of the return rate is compensated for in the PSC occurrence ratio in Fig. 2b. Overall, Arctic PSCs are most abundant between $30^{\circ} \mathrm{W}$ and $90^{\circ} \mathrm{E}$ and north of $70^{\circ} \mathrm{N}$. The pattern of the CALIPSO-derived PSC occurrence rate resembles the MIPAS-based findings in Fig. $6 \mathrm{~b}$ of Spang et al. (2018). Note that Pitts et al. (2018) derived PSC occurrence frequencies for fixed altitudes of $\Theta=500 \mathrm{~K}$ (around $20 \mathrm{~km}$ ) and that the PSC area in their Fig. 24 is thus smaller than in- 

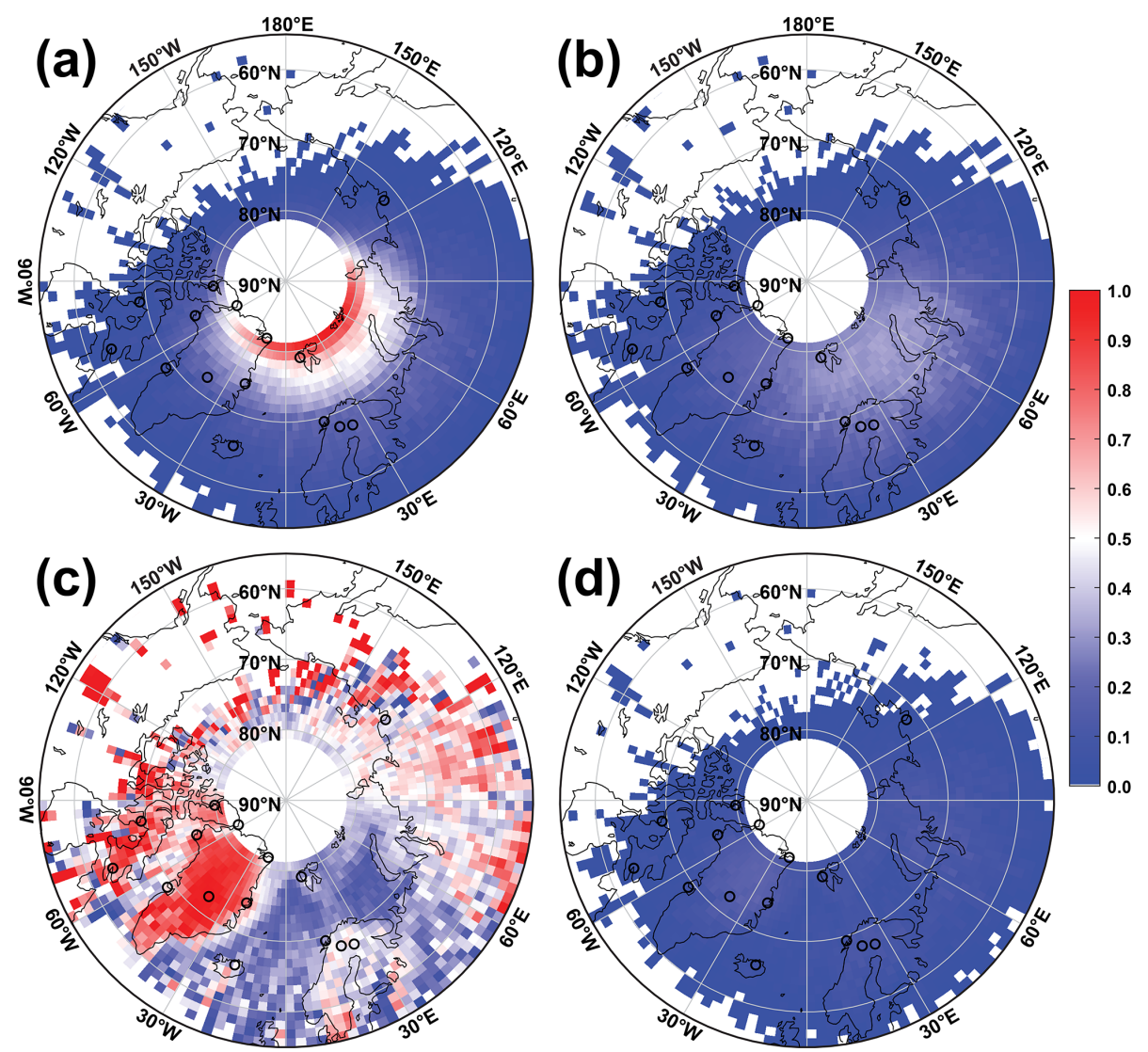

Figure 2. Normalised number of CALIPSO profiles with PSCs detected over the Arctic (a, scaled to maximum count of 2478), ratio of CALIPSO profiles with PSCs detected versus all CALIPSO profiles (with and without PSCs detected) for the same time period (b, PSC occurrence rate), ratio of CALIPSO profiles with favourable tropospheric cloud conditions for ground-based lidar measurements (no or only transparent clouds) and PSCs detected versus all CALIPSO profiles with PSCs detected for the same time period (c), and ratio of CALIPSO profiles with favourable tropospheric cloud conditions for ground-based lidar measurements and PSCs detected versus all CALIPSO profiles for the same time period (d). Black circles mark the locations of lidar ground stations shown in Fig. 1 and listed in Table 1.

ferred from considering all PSC height levels as done here. Figure $2 \mathrm{a}$ and $\mathrm{b}$ also shows that the geography of the Arctic means that most ground stations are located in areas of relatively low PSC occurrence. This is levelled by the normalised occurrence rate of suitable conditions for ground-based observations presented in Fig. $2 \mathrm{c}$ and d. The difference between the two displays is that Fig. $2 \mathrm{c}$ is normalised to the number of all PSC-containing CALIPSO profiles, while Fig. $2 \mathrm{~d}$ is normalised to all CALIPSO profiles. The region of highest PSC occurrence rate over the northern Atlantic coincides with the highest occurrence of opaque tropospheric clouds. While Ny Alesund could potentially observe the most PSCs in the Arctic, the occurrence rate of good conditions for ground-based lidar measurements is much lower than at the other Arctic stations. In contrast, sites on Greenland and in the Canadian Arctic show almost no opaque clouds but - with the exception of Villum - also feature a low occurrence rate of PSCs. A similar situation though with a generally lower rate of suitable conditions for ground-based observations is found for Alomar, Esrange, and Sodankylä. However, these sites pro- vide much easier access than the other more remote locations. Tiksi is a station that could potentially provide information on PSCs over the Siberian Arctic.

The occurrence rate of PSCs with different chemical compositions in the Arctic for all-sky conditions is shown in Fig. 3. Here and in the following closer look at Arctic PSCs, normalisation is done with respect to all CALIPSO profiles that contain PSCs (analogous to Fig. 2c) rather than all CALIPSO profiles (as in Fig. 2b and d). Figure 3 reveals that STS and NAT mixture are most abundant with a region of maximum STS occurrence over the northern Atlantic and southern Greenland. The occurrence rates of NAT enhanced and ice are well below $10 \%$ and neither shows an area of pronounced occurrence. The distribution of wave ice in Fig. 3e shows that this composition is restricted regionally to southeastern Greenland, around Iceland, southern Svalbard, the Scandinavian mountain range, and Novaya Zemlya.

Figure 4 provides a local quantification of the Arctic-wide display in Fig. 3 for the selected Arctic sites in Table 1 in the form of the occurrence rate of different PSC composi- 

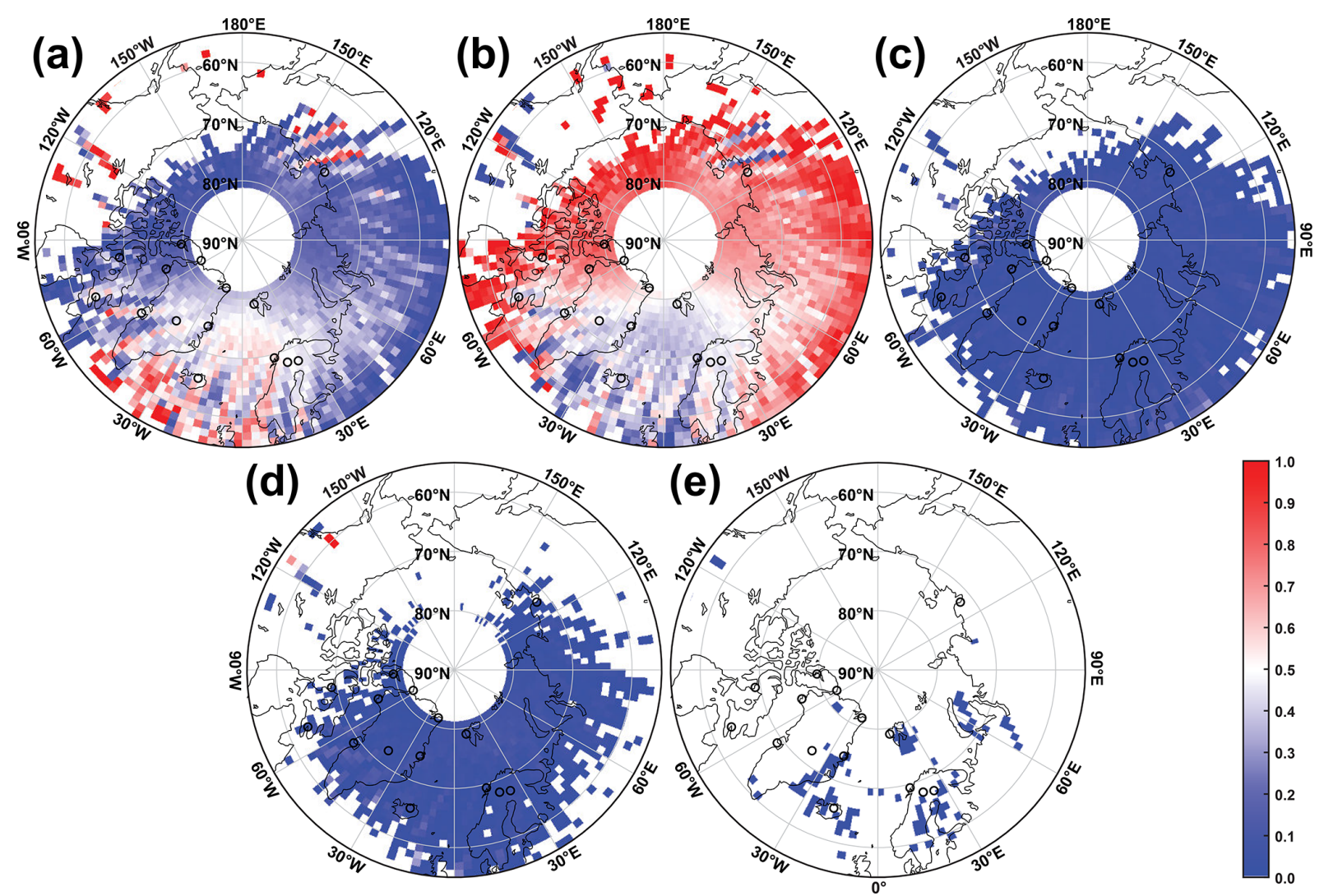

Figure 3. Normalised occurrence rate of CALIPSO height bins that contain (a) STS, (b) NAT mixture, (c) NAT enhanced, (d) ice, and (e) wave ice for all-sky conditions in the Arctic.

tions as seen by a spaceborne instrument (all-sky conditions, same as in Fig. 3), a ground-based lidar with CALIPSOsynchronous measurement protocol operated during every single CALIPSO overpass (no or only transparent clouds are present in the troposphere), and a CALIPSO-synchronously operated ground-based instrument that is affected by cloudiness and other measurement-inhibiting factors (one-third of randomly selected CALIPSO profiles in the presence of no or only transparent clouds). For the entire Arctic, the spaceborne view gives a smaller fraction of NAT mixture compared to the ground-based view, because the regional minimum in the occurrence rate of NAT mixture (Fig. 3b) covers the location of most of the considered ground stations. This is balanced by a larger fraction of STS for the entire Arctic compared to most ground stations. The occurrence rates of NAT enhanced, ice, and wave ice are marginal with a total contribution of less then $10 \%$ of all observed PSC height bins. Tropospheric cloudiness would allow for ground-based observations in only about $42 \%$ of all Arctic CALIPSO PSC profiles. This causes the slight difference between the three bars related to Arctic-wide observations in Fig. 4.

The localised view for 15 ground stations in the Arctic reveals the impact of tropospheric cloudiness on the statistics on PSC microphysical properties as expected from
Fig. 3. Alert and Eureka in the Canadian Arctic and Summit, Thule, and Villum on Greenland, where the conditions for ground-based observations are best (see Fig. 2c), show little difference between the spaceborne and the ground-based view. Differences in PSC statistics at those sites would more likely be related to the imperfect sampling of a ground-based instrument related to cloudiness and other measurementinhibiting factors (ground-based scenario 2). The smallest amount of observed CALIPSO PSC profiles is found for Igloolik (183), Iqualuit (249), Myvatn (918), Qeqertarsuaq (848), and Tiksi (326) compared to the other sites where this number ranges from 2080 for Esrange to 7573 for Ny Ålesund. Consequently, PSC statistics at these sites are much more sensitive to cloudiness and further sub-sampling. A considerable difference between the spaceborne and groundbased view is found in the European Arctic, particularly at Myvatn and Sodankylä. The occurrence rate of STS (ice) is underestimated (overestimated) at Esrange, Myvatn, and Sodankylä, while the opposite is found at Alomar and Ny Ålesund. The ratio of the number of PSC height bins representing the ground-based versus the spaceborne view is given in the third column of Table 1 and allows for the ranking of the ground stations with respect to the occurrence rate of suitable conditions for ground-based measurements. 


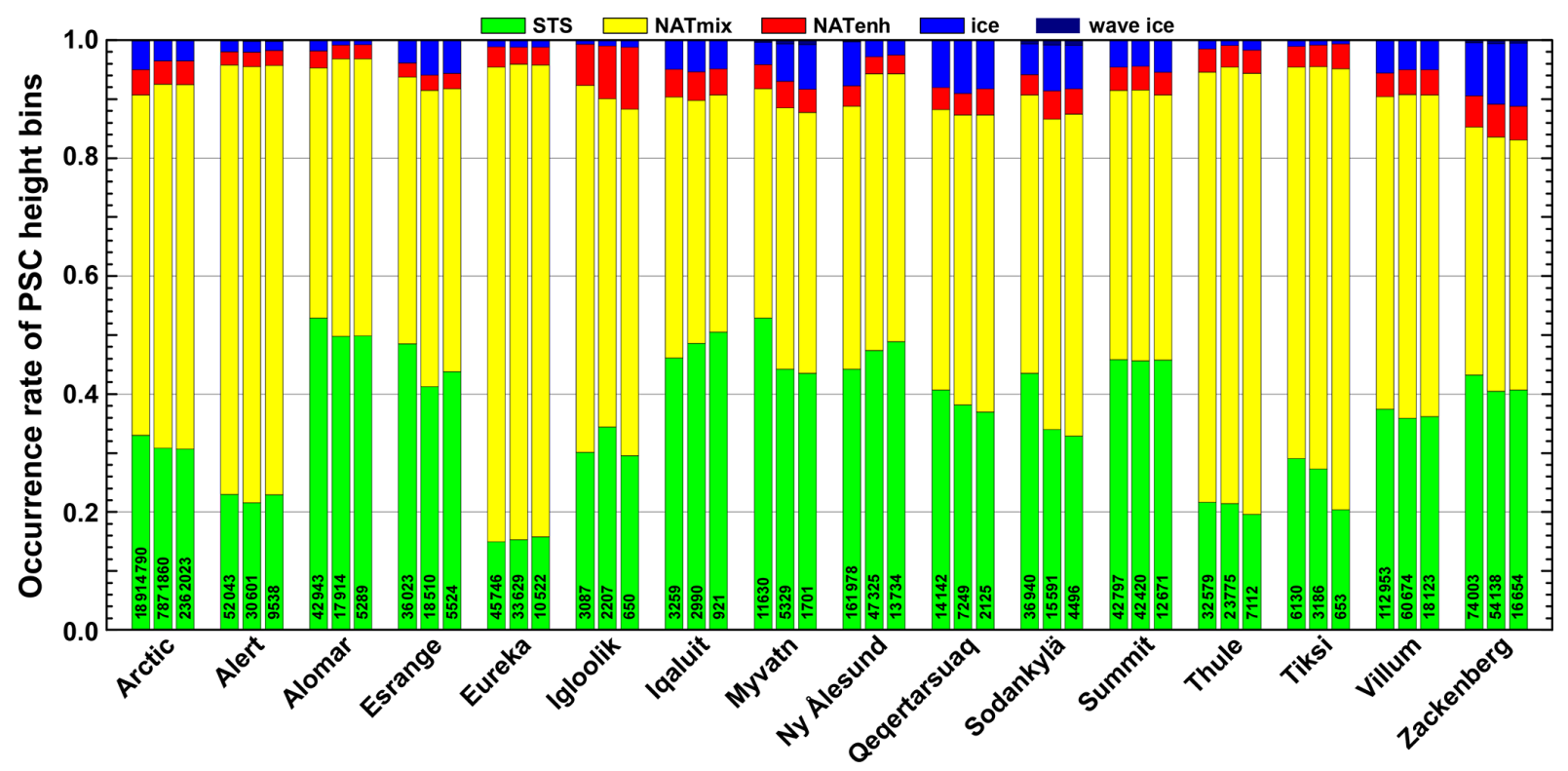

Figure 4. Occurrence rate of STS (green), NAT mixtures (yellow), NAT enhanced (red), ice (blue), and wave ice (dark blue) for the entire Arctic as well as for the Arctic ground stations listed in Table 1. The three bars per site refer to (i) all-sky conditions in the troposphere (the view of a spaceborne lidar, left, not possible with ground-based instruments), (ii) conditions with no tropospheric clouds or transparent clouds only (the view of a ground-based lidar with CALIPSO-synchronous measurement protocol operated during every single CALIPSO overpass, middle), and (iii) one-third of randomly selected profiles from observations with no tropospheric clouds or transparent clouds only (the view of a CALIPSO-synchronously operated ground-based instrument that is affected by cloudiness and other measurement-inhibiting factors, right). Numbers refer to the total number of considered PSC height bins per configuration.

Apart from the different effect of tropospheric cloudiness, Fig. 4 also reveals that statistics of PSC microphysical properties can vary with location. Alert, Eureka, and Thule show STS (NAT mixture) occurrence rates below (above) the Arctic mean of about $30 \%(60 \%)$, while the opposite is the case at Alomar, Esrange, Iqaluit, Myvatn, Ny Ålesund, and Summit where the occurrence rate of STS exceeds $40 \%$ and that of NAT mixture stays below $40 \%$. The highest and lowest occurrence rates of NAT enhanced are found at Igloolik and Alomar, respectively. The other sites show values that are mostly in line with the Arctic mean. Ice is most abundant at Myvatn, Qeqertarsuaq, Sodankylä, and Zackenberg and rarely observed at Alert, Alomar, Eureka, Thule, and Tiksi. Contributions of wave ice are noticeable only at Myvatn, Sodankylä, and Zackenberg (see Fig. 3e) and negligible at the other sites.

\subsection{Antarctic observations}

Figure 5a and $\mathrm{b}$ show that CALIPSO PSC profiles in the Antarctic are nearly equally distributed around the pole with a higher occurrence rate at higher latitudes. The same is found in the MIPAS climatology (Spang et al., 2018). Tropospheric cloudiness related to conditions that support groundbased lidar measurements (Fig. 5c and d) is most abundant inland, whereas the majority of Antarctic stations is located at the coast to keep logistics manageable. As for the Green- land Ice Sheet, the elevation of the better part of Antarctica translates into a complete absence of low-level clouds - the biggest antagonist to atmospheric lidar measurements. Cloudiness is largest upwind from the Antarctic Peninsula. The final column in Table 1 confirms that the lowest occurrence rate of favourable conditions for ground-based lidar measurements of PSCs is found at Marimbio (43\%) and San Martín (45\%), which are located on the Antarctic Peninsula. The opposite, i.e. an occurrence rate of unity, is true for Concordia and Vostok on the Antarctic Plateau.

The maps of the occurrence rates of different PSC compositions in the Antarctic during all-sky conditions in Fig. 6 show that STS and NAT enhanced are rather homogeneously distributed. A regional minimum in the occurrence of NAT enhanced is found over the West Antarctic Ice Sheet, the Weddell Sea, and parts of Queen Maud Land. This is compensated by higher occurrence rates of ice. As in the Arctic, wave ice occurs more locally and is restricted to the Antarctic Peninsula and the border between the Ross Sea and Victoria Land. Despite their layer-based approach on PSC occurrence frequency, Fig. 19 in Pitts et al. (2018) presents similar findings regarding the distribution of STS, NAT, and ice.

The statistics of Antarctic PSC microphysical properties are shown in Fig. 7 and vary with location. There are, however, two noticeable differences compared to the situation in the Arctic. Firstly, there is generally little difference in the statistics related to the spaceborne and ground-based 

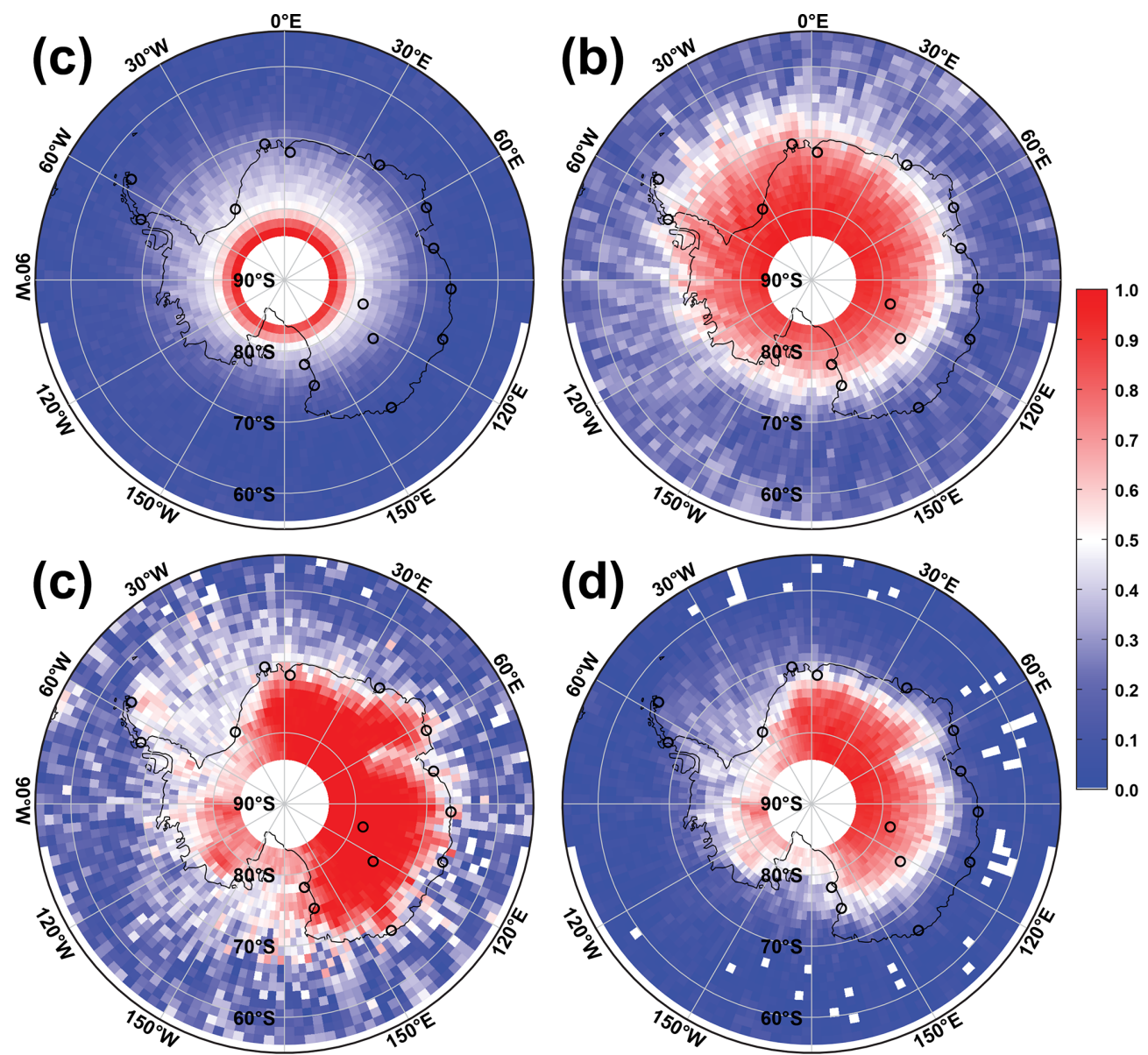

Figure 5. Same as Fig. 2 but for the Antarctic. The display in (a) is scaled to a maximum count of 2001.

view. This is because opaque clouds are less abundant in the Antarctic compared to the Arctic. It is therefore more likely to find reasonable agreement between ground-based an spaceborne PSC observations at Antarctic stations (Snels et al., 2019) and to observe the same long-term statistics for Antarctic PSCs from ground and space. Secondly, sites such as McMurdo and Vostok show statistics that resemble those obtained for the entire Antarctic. The largest occurrence rates of STS are found at Marimbio, Neumayer III, San Martín, and Troll. However, these values do not exceed those for the entire Antarctic by more than 10 percentage points. The lowest occurrence rate of STS is found at Casey with a difference of also about 10 percentage points compared to the Antarctic mean. Casey is also the station with the highest occurrence rate of NAT mixture followed by Mirny. In addition, these two stations show almost no ice PSCs. The lowest rate of NAT mixture and the highest rate of ice $(45 \%-50 \%)$ is found at Belgrano II, as this is the only site located in the regional minimum (maximum) of the occurrence rate of NAT mixture (ice) revealed in Fig. 6. All other sites show ice occurrence rates below the Antarctic average. Wave ice is found only at Jang Bogo (1\%) and McMurdo (0.5\%).

\subsection{Location assessment}

Figure 8 combines the information on the absolute and relative occurrence of PSCs with the occurrence rate of tropospheric conditions that support PSC observations with ground-based lidar. This display helps to assess the likelihood for obtaining suitable amounts of data for studying PSCs from ground-based lidar observations at the sites considered in this study. For the sites to the left of the dashed line that marks 2000 available CALIPSO PSC profiles, the number of PSC profiles in combination with the PSC occurrence rate is too low to consider the establishment of a new lidar station for PSC observations. To the right of the dashed line, further separation is provided by the grey line that represent a scaled PSC coverage. The most suitable stations for PSC observations from ground can be found to the right of this line, because they combine a high PSC occurrence rate and a large number of identified PSC profiles with a high rate of favourable conditions for PSC observations from ground (upper right corner). Of the established PSC observatories only Concordia, Eureka, and McMurdo fall into this category. At Ny Ålesund, the large number of PSC profiles together with 

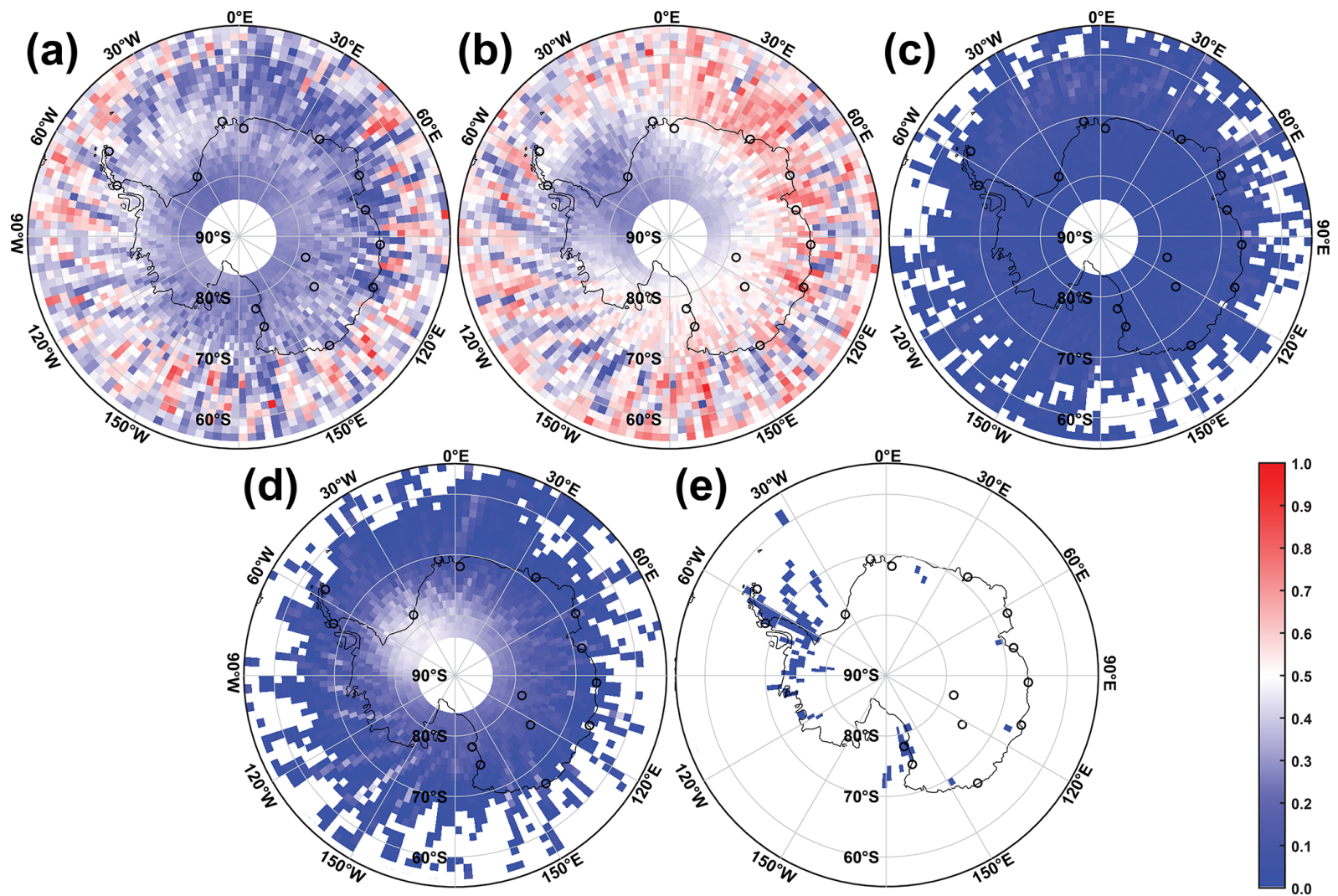

Figure 6. Same as Fig. 3 but for the Antarctic.

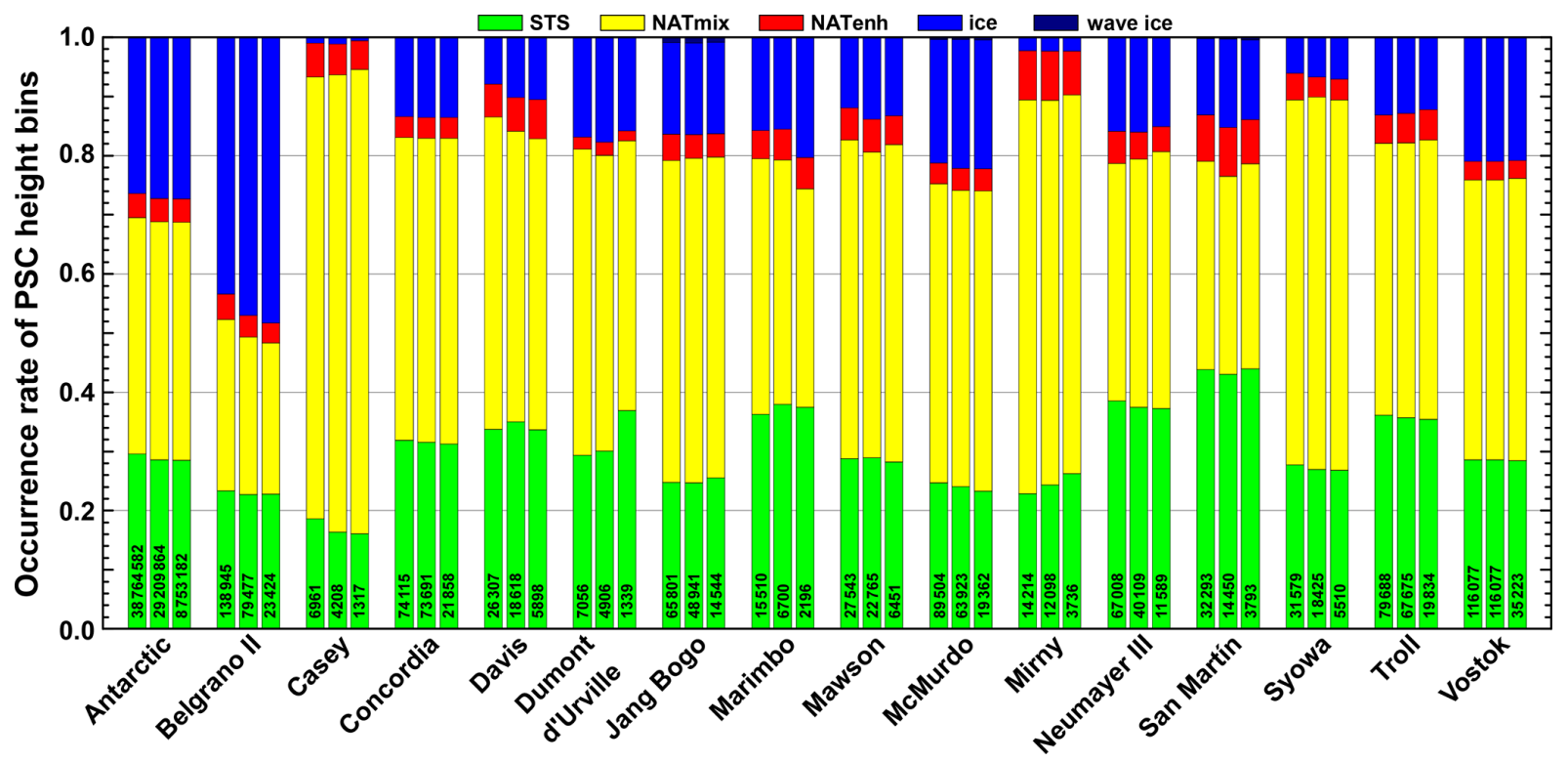

Figure 7. Same as Fig. 4 but for Antarctic observations. 


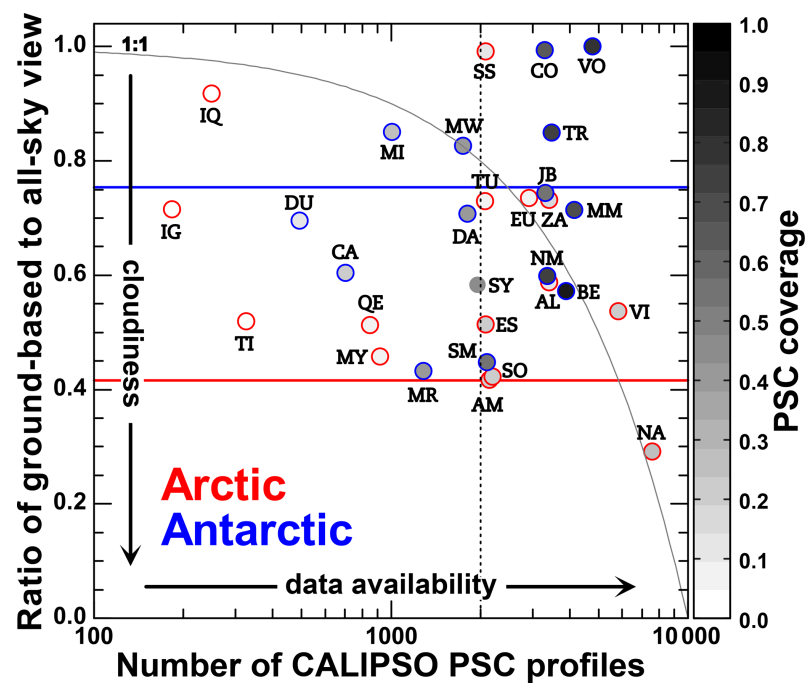

Figure 8. Number of CALIPSO PSC profiles in the $4^{\circ} \times 4^{\circ}$ grid box centred around the Arctic (red) and Antarctic (blue) ground stations listed in Table 1 versus the ratio of PSC height bins as observed by a ground-based and a spaceborne lidar (third and sixth columns in Table 1). The colour coding refers to PSC coverage (ratio of PSC-containing profiles to all profiles) as shown in Figs. 2b and 5b. Horizontal lines mark the values for the entire Arctic and Antarctic, respectively. The vertical dashed line separates stations with more than 2000 CALIPSO PSC profiles from those with fewer observations. The grey line marks a scaled PSC coverage defined as $(10000-x) / 10000$. Stations to the right of this line show a combination of tropospheric cloudiness and PSC coverage that indicates favourable conditions for ground-based lidar measurements. Stations abbreviations and markings for sites with published PSC climatologies are given in Table 1.

the high PSC occurrence rate (see Fig. 2a and b, the PSC coverage of 0.29 at $\mathrm{Ny}$ Ålesund is the largest of all Arctic station) balances the measurement-inhibiting effect of a high occurrence rate of tropospheric clouds. Note that the assessment in Fig. 8 is based entirely on atmospheric conditions and does not consider infrastructural challenges such as the accessibility, power supply, or availability of facilities at the respective sites; or the training and work load of the stationed personnel. It is because of this that most of the established PSC observatories fall into a region that could be considered less suitable for establishing a ground station for PSC observations. Nevertheless, the trade-off between PSC occurrence and tropospheric cloudiness at those sites still creates conditions that allow for meaningful amounts of PSC observations, as witnessed by the available literature. If new PSC observatories were to be established, the most suitable choices based solely on atmospheric conditions - would be Villum, Summit, Zackenberg, Thule, and Alert in the Arctic and Vostok, Troll, Jang Bogo, Belgrano II, and Neumayer III in the Antarctic.

\section{Summary and conclusions}

There is a rich literature on airborne and ground-based PSC measurements going back to the 1980s. The thus collected time series have been used to obtain statistics of microphysical properties of PSCs in the Arctic and Antarctic. While the impact of using different PSC classifications schemes has been assessed in the past (Achtert and Tesche, 2014), there has not yet been an evaluation of the comparability and the representativeness of the available time series and statistics of ground-based PSC observations. Here, CALIPSO lidar observations of clouds in the troposphere and stratosphere are used to compare statistics of PSC microphysical properties as observed (i) from space and ground and (ii) at different ground stations. The data set shows a strong dependence of PSC microphysical statistics on the location of a ground station in both the Arctic and the Antarctic. In the Arctic, there is the additional combined effect of the inhomogeneous distribution in the occurrence of both PSCs and tropospheric clouds on the representativeness of ground-based PSC observations with respect to all-sky conditions.

The combination of the occurrence rate of PSCs and of suitable conditions for ground-based PSC observations allows us to assess the suitability of a ground station for longterm lidar measurements of PSCs. This suitability is related solely to atmospheric conditions and does not consider challenges with respect to logistics, personnel, or training. According to this definition, measurements at more suitable sites will require less measurement effort to obtain a data set that can be used to infer statistically significant PSC data. This knowledge is important as ground-based lidars are generally more advanced than spaceborne instruments and allow researchers to independently retrieve backscatter and extinction coefficients as well as the particle linear depolarisation ratio at multiple wavelengths and at a better signal-to-noise ratio. Their measurements are therefore invaluable for a better understanding of processes related to PSC formation and persistence.

Of the established PSC observatories only Concordia, Eureka, McMurdo, and Ny Ålesund are found to fall into a category that provides a good balance between PSC occurrence and tropospheric cloudiness. Dumont d'Urville is at the lower end of available PSC observations, while Esrange, Sodankylä, and Syowa all show only about 1000 CALIPSO PSC profiles during conditions for ground-based measurements. The occurrence rate of PSCs in the Arctic is much lower than in the Antarctic. Hence, the assessment presented here is particularly important for Arctic sites. Considering only atmospheric conditions, it is found that Villum, Summit, Zackenberg, Thule, and Alert would be the best choices for establishing new PSC observatories with state-of-the-art lidar instruments in the Arctic. In the Antarctic, this is the case for Vostok, Troll, Mawson, Jang Bogo, Belgrano II, and Neumayer III. 
The strong dependence of PSC formation on temperature suggests a crucial role of processes that enhance local cooling (Carslaw et al., 1998; Teitelbaum et al., 2001). These include synoptic or mesoscale events that are generally linked to specific types of tropospheric cloudiness. It is therefore reasonable to expect a connection between tropospheric cloudiness and the occurrence of PSCs and maybe even PSCs of different chemical composition. Initial studies focussing on individual winters in the Arctic (Achtert et al., 2012) and Antarctic (Wang et al., 2008; Adhikari et al., 2010) show that particularly high and deep-convective cloud systems have a strong effect on PSC formation. This indicates that tropospheric meteorology might be an important driver for the interannual variability in PSC formation and ozone hole recovery. While CALIPSO is operational since 2006, there has not yet been a thorough assessment of the dependence of the occurrence of different PSC compositions on tropospheric cloudiness. In the future, the combined CALIPSO data set of clouds in the troposphere and stratosphere presented here will be used to investigate this connection. In addition, the methodology presented here can be easily adapted to assess the effect of low-level clouds on tropospheric observations. For instance, it can be used to find locations for measurement campaigns or long-term observatories at which the measurement-inhibiting effect of opaque clouds has a minimum impact on the observational cover of mid-level or high clouds and elevated tropospheric and stratospheric aerosol layers.

Data availability. CALIPSO Cloud Profile data were obtained from the ICARE Data and Services Center (https://www.icare. univ-lille.fr/, last access: 8 January 2021, CALIPSO Cloud Profile data, 2021). CALIPSO polar stratospheric cloud mask v2 data are available from Michael C. Pitts upon request.

Author contributions. MT and PA conceived the study, developed the methodology, and analysed the data. CALIPSO polar stratospheric cloud mask v2 data were provided by MCP. All authors contributed to the discussion of the data and the preparation of the article.

Competing interests. The authors declare that they have no conflict of interest.

Acknowledgements. We thank the CALIPSO Science Team for providing CALIPSO data for tropospheric clouds.

Financial support. This work was supported by the FrancoGerman Fellowship Programme on Climate, Energy, and Earth System Research (Make Our Planet Great Again - German Research Initiative, MOPGA-GRI, grant number 57429422) of the German
Academic Exchange Service (DAAD), funded by the German Ministry of Education and Research.

Review statement. This paper was edited by Farahnaz Khosrawi and reviewed by Vincent Noel and one anonymous referee.

\section{References}

Achtert, P. and Tesche, M.: Assessing lidar-based classification schemes for polar stratospheric clouds based on 16 years of measurements at Esrange, Sweden, J. Geophys. Res., 119, 13861405, https://doi.org/10.1002/2013JD020355, 2014.

Achtert, P., Karlsson Andersson, M., Khosrawi, F., and Gumbel, J.: On the linkage between tropospheric and Polar Stratospheric clouds in the Arctic as observed by space-borne lidar, Atmos. Chem. Phys., 12, 3791-3798, https://doi.org/10.5194/acp12-3791-2012, 2012.

Adhikari, L., Wang, Z. and Liu, D.: Microphysical properties of Antarctic polar stratospheric clouds and their dependence on tropospheric cloud systems, J. Geophys. Res., 115, D00H18, https://doi.org/10.1029/2009JD012125, 2010.

Adriani, A., Massoli, P., di Donfrancesco, G., Cairo, F., Moriconi, M., and Snels, M.: Climatology of polar stratospheric clouds based on lidar observations from 1993 to 2001 over McMurdo Station, Antarctica, J. Geophys. Res., 109, D24211, https://doi.org/10.1029/2004JD004800, 2005.

Blum, U., Fricke, K. H., Müller, K. P., Siebert, J., and Baumgarten, G.: Long-term lidar observations of polar stratospheric clouds at Esrange in northern Sweden, Tellus B, 57, 412-422, 2005.

CALIPSO Cloud Profile data: Date were obtained from the ICARE Data and Services Center, available at: https://www. icare.univ-lille.fr/, last access: 8 January 2021.

Carslaw, K. S., Wirth, M., Tsias, A., Luo, B. P., Dornbrack, A., Leutbecher, M., Volkert, H., Renger, W., Bacmeister, J. T., Reimers, E., and Peter, T. H.: Increased stratospheric ozone depletion due to mountain-induced atmospheric waves, Nature, 391, 675-678, 1998.

Córdoba-Jabonero, C., Guerrero-Rascado, J. L., Toledo, D., Parrondo, M., Yela, M., Gil, M., and Ochoa, H. A.: Depolarization ratio of polar stratospheric clouds in coastal Antarctica: comparison analysis between ground-based Micro Pulse Lidar and spaceborne CALIOP observations, Atmos. Meas. Tech., 6, 703-717, https://doi.org/10.5194/amt-6-703-2013, 2013.

David, C., Bekki, S., Godin, S., Mégie, G., and Chipperfield, M. P.: Polar Stratospheric Clouds climatology over Dumont d'Urville between 1989 and 1993 and the influence of volcanic aerosols on their formation, J. Geophys. Res., 103, 2216322180, https://doi.org/10.1029/98JD01692, 1998.

Donovan, D. P., Fast, H., Makino, Y., Bird, J. C., Carswell, A. I., Davies, J., Duck, T. J., Kaminski, J. W., McElroy, C. T., Mittermeiter, R. L., and Pal, S. R.: Ozone, column ClO, and PSC measurements made at the NDSC Eureka observatory $(80 \mathrm{~N}, 86 \mathrm{~W})$ during the spring of 1997, Geophys. Res. Lett., 24, 2709-2712, 1997.

Kogure, M., Nakamura, T., Ejiri, M. K., Nishiyama, T., Tomikawa, Y., Tsutsumi, M., Suzuki, H., Tsuda, T. T., Kawahara, T. D., and Abo, M.: Rayleigh/Raman lidar observations of gravity 
wave activity from 15 to $70 \mathrm{~km}$ altitude over Syowa $\left(69^{\circ} \mathrm{S}\right.$, $\left.40^{\circ} \mathrm{E}\right)$, the Antarctic, J. Geophys. Res.-Atmos., 122, 7869-7880, https://doi.org/10.1002/2016JD026360, 2017.

Langenbach, A., Baumgarten, G., Fiedler, J., Lübken, F.-J., von Savigny, C., and Zalach, J.: Year-round stratospheric aerosol backscatter ratios calculated from lidar measurements above northern Norway, Atmos. Meas. Tech., 12, 4065-4076, https://doi.org/10.5194/amt-12-4065-2019, 2019.

Liu, Z., Vaughan, M., Winker, D., Kittaka, C., Getzewich, B., Kuehn, R., Omar, A., Powell, K., Trepte, C., and Hostetler, C.: The CALIPSO lidar cloud and aerosol discrimination: Version 2 algorithm and initial assessment of performance, J. Atmos. Ocean. Tech., 26, 1198-1213, 2009.

Lowe, D. and MacKenzie, A. R.: Polar stratospheric cloud microphysics and chemistry, J. Atmos. Sol.-Terr. Phys., 70, 13-40, https://doi.org/10.1016/j.jastp.2007.09.011, 2008.

Massoli, P., Maturilli, M., and Neuber, R.: Climatology of Arctic polar stratospheric clouds as measured by lidar in Ny-Ålesund, Spitsbergen $\left(79^{\circ} \mathrm{N}, 12^{\circ} \mathrm{E}\right)$, J. Geophys. Res., 111, D09206, https://doi.org/10.1029/2005JD005840, 2006.

Müller, M., Neuber, R., Beyerle, G., Kyrö, E., Kivi, R., and Wöste, L.: Non-uniform PSC occurrence within the Arctic Polar Vortex, Geophys. Res. Lett., 28, 4175-4178, https://doi.org/10.1029/2001GL013799, 2001.

Neely, R. R., Hayman, M., Stillwell, R., Thayer, J. P., Hardesty, R. M., O’Neill, M., Shupe, M. D., and Alvarez, C.: Polarization Lidar at Summit, Greenland, for the Detection of Cloud Phase and Particle Orientation, J. Atmos. Ocean. Tech., 30, 1635-1655, https://doi.org/10.1175/JTECH-D-12-00101.1, 2013.

Pitts, M. C., Poole, L. R., and Thomason, L. W.: CALIPSO polar stratospheric cloud observations: second-generation detection algorithm and composition discrimination, Atmos. Chem. Phys., 9, 7577-7589, https://doi.org/10.5194/acp-9-7577-2009, 2009.

Pitts, M. C., Poole, L. R., Lambert, A., and Thomason, L. W.: An assessment of CALIOP polar stratospheric cloud composition classification, Atmos. Chem. Phys., 13, 2975-2988, https://doi.org/10.5194/acp-13-2975-2013, 2013.

Pitts, M. C., Poole, L. R., and Gonzalez, R.: Polar stratospheric cloud climatology based on CALIPSO spaceborne lidar measurements from 2006 to 2017, Atmos. Chem. Phys., 18, 1088110913, https://doi.org/10.5194/acp-18-10881-2018, 2018.
Santecesaria, V., MacKenzie, A. R., and Stefanutti, L.: A climatological study of Polar Stratospheric Clouds (1989-1997) from LIDAR measurements over Dumont d'Urville (Antarctica), Tellus B, 53, 306-321, https://doi.org/10.1034/j.16000889.2001.01155.x, 2001.

Shibata, T., Sato, K., Kobayashi, H., Yabuki, M., and Shiobara, M.: Antarctic polar stratospheric clouds under temperature perturbation by non-orographic inertia gravity waves observed by micropulse lidar at Syowa Station, J. Geophys. Res., 108, 4105, https://doi.org/10.1029/2002JD002713, 2003.

Snels, M., Scoccione, A., Di Liberto, L., Colao, F., Pitts, M., Poole, L., Deshler, T., Cairo, F., Cagnazzo, C., and Fierli, F.: Comparison of Antarctic polar stratospheric cloud observations by ground-based and space-borne lidar and relevance for chemistry-climate models, Atmos. Chem. Phys., 19, 955-972, https://doi.org/10.5194/acp-19-955-2019, 2019.

Snels, M., Colao, F., Shuli, I., Scoccione, A., De Muro, M., Pitts, M., Poole, L., and di Liberto, L.: Quasi-coincident Observations of Polar Stratospheric Clouds by Ground-based Lidar and CALIOP at Concordia (Dome C, Antarctica) from 2014 to 2018, Atmos. Chem. Phys. Discuss., https://doi.org/10.5194/acp-2020972, in review, 2020.

Solomon, S.: Stratospheric ozone depletion: A review of concepts and history, Rev. Geophys., 37, 275-316, 1999.

Spang, R., Hoffmann, L., Müller, R., Grooß, J.-U., Tritscher, I., Höpfner, M., Pitts, M., Orr, A., and Riese, M.: A climatology of polar stratospheric cloud composition between 2002 and 2012 based on MIPAS/Envisat observations, Atmos. Chem. Phys., 18, 5089-5113, https://doi.org/10.5194/acp-18-5089-2018, 2018.

Teitelbaum, H., Moustaoui, M., and Fromm, M.: Exploring polar stratospheric cloud and ozone minihole formation: The primary importance of synoptic-scale flow perturbations, J. Geophys. Res., 106, 28173-28188, https://doi.org/10.1029/2000JD000065, 2001.

Wang, Z., Stephens, G., Deshler, T., Trepte, C., Parish, T., Vane, D., Winker, D., Liu, D., and Adhikari, L.: Association of Antarctic polar stratospheric cloud formation on tropospheric cloud systems, Geophys. Res. Lett., 35, L13806, https://doi.org/10.1029/2008GL034209, 2008.

Winker, D. M., Vaughan, M. A., Omar, A. H., Hu, Y., Powell, K. A., Liu, Z., Hunt, W. H., and Young, S. A.: Overview of the CALIPSO Mission and CALIOP Data Processing Algorithms, J. Atmos. Ocean. Tech., 26, 2310-2323, https://doi.org/10.1175/2009JTECHA1281.1, 2009. 